\title{
ERA BARU TELEVISI DALAM PANDANGAN KONVERGENSI MEDIA
}

\author{
Rizca Haqqu \\ Program Studi Ilmu Komunikasi, Fakultas Komunikasi dan Bisnis \\ Telkom University \\ Jalan Telekomunikasi Jalan Terusan Buah Batu, Sukapura, Dayeuhkolot \\ Bandung, Jawa Barat 40257 \\ No.HP: 081325225900,E-mail: rizcahaqqu@telkomuniversity.ac.id
}

\begin{abstract}
ABSTRAK
Pesatnya perkembangan teknologi berbanding lurus dengan perekembangan media massa. Hadirnya internet dalam kehidupan keseharian masyarakat berdampak besar terhadap keberlangsungan media konvensional. Salah satunya adalah media televisi yang mau tidak mau harus berbenah diri menyambut era baru yaitu televisi digital. Kemunculan media baru ini mengubah cara masyarakat mendapatkan informasi melalui media. Untuk dapat terus berkompetisi sebagai sumber informasi yang diminati masyarakat, media televisi harus melakukan sebuah inovasi dengan cara berkonvergensi. Pada penulisan karya ilmiah ini hanya sebatas melakukan kajian literatur dengan model penelitian library research yang bertujuan untuk mengetahui konvergensi media yang dilakukan oleh media televisi khususnya dalam mengubah platform konvensional ke digital.Konvergensi media memungkinkan para profesional di bidang media massa untuk menyampaikan berita dan menghadirkan informasi dan hiburan, dengan menggunakan berbagai macam media. Pemerintah selaku regulator bertanggung jawab penuh menciptakan regulasi yang dapat melindungi segenap elemen masyarakat dari pengaruh buruk media. Regulasi menjadi konsekuensi logis dari permainan simbol budaya yang ditampilkan oleh media konvergen. Tujuannya jelas, yakni agar tidak terjadi tabrakan kepentingan yang menjadikan salah satu pihak menjadi dirugikan. Terutama bagi kalangan pengguna atau publik, pihak ini biasanya menjadi pihak yang paling sering menjadi korban dari implementasi konvergensi.
\end{abstract}

Kata kunci: televisi, konvergensi media, library research

\section{ABSTRACT}

New Era of Television in the Perspective of Media Convergence. The rapid development of technology is directly proportional to the development of mass media. The presence of the internet in people's daily lives has a major impact on the sustainability of conventional media. One of them is television media that inevitably has to improve itself to welcome a new era, namely digital television. The emergence of this new media is changing the way people get information through the media. To be able to continue to compete as a source of information that interests the public, television media must innovate in a way that converges. The writing of this scientific paper is limited to conducting a literature study with a library research model that aims to find out media convergence carried out by television media, especially in changing conventional platforms to digital. Media convergence enables professionals in the mass media field to deliver news and present information and entertainment using a variety of media. The government as the regulator is fully responsible for creating regulations that can protect all elements of society from the bad influence of the media. Regulation becomes a logical consequence of the game of cultural symbols displayed by convergent media. The goal is clear, which is to avoid a conflict of interests that makes one party harmed, especially the users or the public, for they usually become the victim of the implementation of a convergence.

Keywords: television, media convergence, library research 


\section{PENDAHULUAN}

Televisi sebagai media konvensional, dirasa masih tetap eksis menahan genpuran media-media baru yang ada. Berdasarkan hasil survei yang dikembangkan oleh Neilsen televisi masih diminati dan mendapatkan tempat teratas media yang di minati oleh masyarakat Indonesia. Khalayak pada umumnya menyukai televisi dikararenakan karakternya yang praktis akan sebuah informasi dan hiburan yang disajikannya (Sari, 2016).

Perkembangan televisi diikuti dengan bertambahnya stasiun televisi baik lokal maupun nasional dari tahun ke tahun serta diberengai dengan meningkatnya mutu kualitas dan kuantitas menjadikan bukti media televisi masih eksis dikalangan masyarakat. Para kreatif industri pertelevisian tidak pernah berhenti untuk melakukan eksplorasi dan penemuan formula baru dalam menayangkan sebuah program audiovisual yang berkualitas (Suprihono et al., 2019).

Kemunculan internet didalam perkembangan televisi menumbuhkan kolaborasi diantara keduanya, atau biasa disebut dengan istilah konvergensi. Tapscott (1996) dalam bukunya yang berjudul The Digital Economy, Promise and Peril in the Age of Networked Intelligence, menyatakan bahwa telah terjadi perubahan perkembangan industry mesin/otomotif ke bentuk komputer dan jaringan (networking). Masifnya informasi terjadi ketika pola komunikasi yang dibatasi oleh ruang dan waktu menjadi pola komunikasi informasi tanpa batas sehingga tidak mengherankan apabila terjadi perubahan dari media massa konvensional menjadi media massa baru.

Seperti yang telah dijelaskan sebelumnya, pesatnya perkembangan teknologi media massa mencuatkan istilah konvergensi media di kalangan para penggiat media. Romli (2016) dalam penelitiannya menjelaskan bahwa fenomena awal konvergensi media mulai dirasakan pada media cetak dan radio hingga akhirnya mulai merambah ke industri pertelevisian nasional.

Konvergensi dipandang sebagai proses perusahaan media yang sebelumnya terspesialisasi dalam satu platform (seperti cetak, radio, televisi (TV) atau online) sekarang membentuk lebih besar multiplatform konglomerat media. Konvergensi teknologi platform terjadi karena digitalisasi konten media, yang menyebabkan media lama dan baru bertabrakan (Jenkins, 2006). Konvergensi media bukan sekadar pergeseran teknologi, tetapi mengubah hubungan antara teknologi yang ada, baik dari sisi industri, pasar, genre, maupun khalayak. Konvergensi mengacu pada sebuah proses, tetapi bukan titik akhir. Berkat proliferasi saluran dan portabilitas komputasi baru dan teknologi telekomunikasi, kita dapat menggunakan semua jenis media dan berhubungan satu sama lain. Ponsel bukan sekadar perangkat telekomunikasi; tetapi juga memungkinkan untuk bermain game, mengunduh informasi dari internet, dan menerima serta mengirim foto atau pesan teks.

Dalam pandangan para penggiat media, hadirnya konvergensi dipandang sebagai proses multiplatform konglomerat media yang sebelumnya terspesialisasi dalam satu platform seperti cetak, radio, televisi atau online. Konvergensi teknologi platform terjadi karena digitalisasi konten media, yang menyebabkan media lama dan baru bertabrakan (Jenkins, 2006). Secara lebih khusus konvergensi media bukan sekadar pergeseran teknologi, akan tetapi keberadaan konvergensi mengubah hubungan antara teknologi yang ada, baik dari sisi industri, pasar, genre, maupun khalayak.

Konvergensi mengacu pada suatu proses, tetapi bukan titik akhir. Berkat kecangihan dan pesatnya perkembangan teknologi media, maka masyarakat dapat menggunakan semua jenis media dan berhubungan satu sama lain. Perkembangan industri televisi konvensional lampat laiun mengalami perubahan dengan hadirnya televisi digital dimana dalam satu layer televisi dapat digunakan berbagai platform yang terkoneksi dengan internet. Selain televisi digital yang sangat mengalami perubahan pesat adalah ponsel yang sekarang fungsinya berubah menjadi smart phone. Ponsel pintar bukan hanya perangkat telekomunikasi; tetapi dimungkinkan juga untuk 
bermain game, mengunduh informasi dari internet, dan menerima serta mengirim foto atau pesan teks, bahkan menyampaikan berita teraktual hanya dalam satu sentuhan.

Berdasarkan sudut pandang industri dampak dari konvergensi media telah dirasakan secara langsung oleh berbagai bidang, misalnya di ranah jurnalistik konvensional telah mengalami perubahan yang sangat signifikan. Jurnalis dituntut untuk menyampaikan sebuah informasi dengan cepat kepada khalayak, atau sekarang disebut sebagai jurnalisme online (Abrar, 2003), malukukan transaksi jual beli dilakukan melalui jejaring sosial bukan secara konvensional dan masih banyak lagi perubahan-perubahan perilaku media dilakangan masyarakat.

Berdasarkan apa yang telah dipaparkan, sebagai penunjang penulisan karya ilmiah, Studi pustaka digunakan dalam penelitian ini sebagai teknik pengumpulan data. Studi pustaka (library research) merupakan teknik pengumpulan data dengan mengadakan studi penelaahan terhadap literatur-literatur, laporan-laporan, buku-buku, dan catatan-catatan yang mempunyai hubungan dengan masalah yang akan dipecahkan. Telaah pustaka lebih dari sekadar melayani fungsi-fungsi yang disebutkan untuk memperoleh data penelitiannya. Dengan kata lain, riset pustaka membatasi kegiatannya hanya pada bahan-bahan koleksi perpustakaan saja tanpa memerlukan riset lapangan (Zed, 2014).

Berbagai wacana tentang konvergensi media mulai marak diperbincangkan oleh kalangan industri. Tak ayal dari fenomena yang mencuat menjadi tema yang menarik para peneliti khususnya peneliti di bidang media. Berdasarkan penjelasan tersebut, penulis ingin melakukan sebuah kajian kepustakaan untuk mengetahui bagaimana tingkat kesiapan pelaku industri media dan pemerintah dalam hal kesiapan menghadapi perubahan media yang biasa dikenal sebagai fenomena konvergensi media khususnya di media televisi.

\section{PEMBAHASAN}

Keberadaan televisi digital dirasa memberikan beberapa keunggulan bagi penggunanya. Seperti halnya internet, televisi digital memungkinkan tersedianya tambahan-tambahan siaran yang lebih interaktif. Keunggulan televisi digital dibandingkan konvensional adalah kualitas gambar dan suara yang lebih baik, dimana penonton seakan menikmati sebuah tayangan layaknya menonton sebuah layar lebar.

Penggabungan antara televisi dan internet memungkinkan tersedianya link antar program serata akses ke arsip digital untuk memperoleh informasiinformasi tambahan seperti program berita dan current affairs; program drama atau komedi dan streaming video yang lazim di dunia internet, termasuk film on demand dan siaran langsung melalui internet (Hastjarjo, 2007). Di samping itu, sistem digital memungkinkan diversifikasi saluran sehingga menjadi saluran multikanal. Hastjarjo (2007) dalam sebuah pandangannya menuturkan bahwa sekalipun hadirnya televisi digital dapat menghadirkan kemungkinan-kemungkinan menarik, akan tetapi realisasinya kemungkinan tidak secepat media yang lain. Secara lebih simpel semua media yang terkoneksi langsung dengan internet disebut sebagai "media baru" di kalangan peneliti.

Hakikat media baru didasarkan pada kemampuannya untuk melanjutkan bentuk media tradisional, baik dari segi fungsi maupun kapasitas. Kemunculan media baru ini, dalam pandangan GuoMing Chen dan Kai Zhang dalam artikelnya New Media and Cultural Identity in the Global Society, melahirkan apa yang disebut "revolusi informasi", setelah sebelumnya revolusi agrikultur dan revolusi industri, dalam peradaban manusia. Media baru memiliki lima fitur: digitality, convergency, interactivity, hypertextuality, and virtuality yang membuatnya berbeda dengan media-media lama yang tradisional (Chen \& Zhang, 2010).

Ketersediaan teknologi pada sistem televisi digital memungkinkan pengembangan layananlayanan interaktif berbasis multimedia dan 
berpotensi tumpang tindih dengan layanan pada media komunikasi lainnya. Maksud dari tumpang tindah adalah konten televisi yang ada tidak selalu dapat disaksikan melalui media kovensional, tetapi dapat dinikmati melalui media komunikasi lain berbasis audiovisual. Diperlukan kajian-kajian yang lebih mendalam terhadap fenomena konvergensi pada teknologi informasi dan komunikasi saat ini. Hal ini dikarenakan besarnya peranan pasar dan regulasi, selain teknologi, yang memengaruhi arah perkembangannya sehingga pembahasan konvergensi ini dapat dijadikan acuan bagi pelaku industri televisi.

Konvergensi tidak akan terjadi sampai Anda memiliki segala seuatu dalam bentuk digital, yaitu ketika konsumen dapat dengan mudah menggunakannya pada semua bentuk peralatan yang berbeda. Jadi, ketika kita membahas tiga jenis media terpenting: foto, musik, dan video, kemajuan yang dapat memberikan orang fleksibilitas terhadap penggunaan jenis media ini sangatlah penting (Cooper, 2018).

Di sisi lain pesatnya perkembangan teknologi belum sepenuhnya masyarakat Indonesia mampu memanfaatkan keberadaan teknologi informasi dan komunikasi dikarenakan keterbatasan akses di setiap daerah. Hal ini bertolak belakang dengan negara tetangga seperti Malaysia, Singapura, Australia, dan Filipina dimana akses teknologi internet terbilang mudah dan murah. Keberadaan internet dinilai sangat penting untuk dapat mengakses informasi publik yang bermanfaat seperti informasi pendidikan, kesehatan, ataupun informasi lain yang bisa meningkatkan produktivitas dan kesejahteraan.

Dilihat dari sudut pandang teoretis dan praktis, kolaborasi antara media massa konvensional dengan teknologi internet tak ayal menumbuhkan serangkaian konsekuensi baru. Pada tataran teoretik, pengertian komunikasi massa konvensional perlu dilakukan kajian-kajian ulang lebih mendalam mengikuti perkembangan jaman. Keberadaan media konvergen memunculkan karakter baru yang makin interaktif, dimana penggunanya mampu berkomunikasi secara langsung dan memperoleh konsekuensi langsung atas pesan (Severin, J. W., \& James, 2001).

Konvergensi media memberikan kesempatan kepada khalayak untuk dapat berinteraksi dengan media massa dan bahkan mengisi konten media massa. khalayak sekarang dapat mengontrol kapan, di mana, dan bagaimana mereka mengakses informasi, dalam berbagai jenisnya. Tayangan televisi tidak selalu di akses didepan layar televisi konvensional akan tetapi dapat dikases dimana saja kapan saja dengan berbagai platform.

Perubahan konsep massa dalam sebuah konvergensi media dikarenakan adanya perpaduan ciri-ciri komunikasi massa dan komunikasi antarpribadi. Komunikasi massa berdasarkan sudut pandang konvensional diartikan sebagai kesatuan khalayak yang anonim dan teralienasi sehingga pesan yang disampaikan kepadanya pun besarbesaran (massive). Akan tetapi dalam pandangan media konvergen justru terjadi proses demassivikasi. Media konvergen menyebabkan derajat massivitas massa berkurang karena komunikasinya makin personal dan interaktif.

Pada tataran praktis, konvergensi media menghadirkan isu-isu penting di bidang ekonomi, sosial, kebudayaan, politik, dan pendidikan. Lembaga pendidikan akan dituntut untuk mampu menyediakan lulusan berkualitas dan memiliki kematangan akademis sekaligus kapabilitas praktik yang berbeda dengan sebelumnya. Dalam konteks ini, dunia pendidikan pada masa mendatang dihadapkan pada tantangan-tantangan pembenahan kurikulum agar sesuai betul dengan laju teknologi yang tidak terbendung. Dunia kerja akan datang mensyaratkan kualifikasi keterampilan baru di setiap pekerjaan yang berhubungan dengan konvergensi teknologi.

Dari sudut pandang bisnis, konvergensi pada media televisi juga berarti peluang profesi baru. Munculnya istilah konvergensi memberikan peluang baru kepada pengelola media untuk memperluas pilihan publik. konvergensi juga berpeluang menciptakan kelompok dominan baru yang akan menjadi penguasa pasar, konsentrasi kepemilikan 
salah satunya. Sektor-sektor media yang berbeda akan bergabung dan menghidupkan konglomerasi.

Kekhawatiran sebagian kalangan bahwa isi media konvergen di bagian tertentu akan mendegradasi moral generasi muda merupakan salah satu poin penting yang harus dipikirkan oleh para pelaku media konvergen. Persoalan terakhir ini menarik karena perkembangan teknologi umumnya selalu mendahului regulasi. Dengan kata lain, regulasi hampir selalu ketinggalan jika dibandingkan dengan perkembangan teknologi komunikasi. Fungsi pemerintah sebagai regulatory agent adalah menjaga hubungan dengan pasar dan masyarakat sipil agar tidak terjadi dominasi antarketiganya.

Dari sudut pandang kebudayaan, pola perilaku masyarakat akan berubah seiring dengan perkembangan media konvergen. Digitalisasi media menyebabkan kurang pentingnya memisahkan isi media dari sisi produksi, editing, distribusi, dan penyimpanannya. Maka, bentuk dan isi media mendatang akan berubah mengikuti perkembangan teknologi. Cepat atau lambat, pada masa mendatang preferensi masyarakat terhadap media akan beralih dari media konvensional ke media konvergen. Singkatnya, konvergensi akan mengubah hubungan antara teknologi, industri, pasar, gaya hidup, dan khalayak.

\section{SIMPULAN}

Berdasarkan pembahasan yang telah disajikan, dapat disimpulkan bahwa didalam era konvergensi, mau tidak mau media konvensioanal harus mengikuti arus perkembangan zaman. Para pelaku industri terutama dibidang industri kreatif televisi tidak boleh tutup mata melihat kondisi sekarang ini agar tidak terdegradasi dan tergerus kencangnya arus perkembangan teknologi. Disisi lain konvergensi media memungkinkan para profesional di bidang media massa untuk menyampaikan berita dan menghadirkan informasi dan hiburan, dengan menggunakan berbagai macam media. Komunikasi yang sudah dikonvergensikan menyediakan berbagai macam alat untuk penyampaian berita dan memungkinkan konsumen untuk memilih tingkat interaktivitasnya, seraya mereka bisa mengarahkan sendiri penyampaian kontennya.

Pemerintah selaku regulator bertanggung jawab penuh menciptakan regulasi yang dapat melindungi segenap elemen masyarakat dari pegaruh buruk media. Regulasi menjadi konsekuensi logis dari permainan simbol budaya yang ditampilkan oleh media konvergen. Tujuannya jelas, yakni agar tidak terjadi tabrakan kepentingan yang menjadikan salah satu pihak menjadi dirugikan. Terutama bagi kalangan pengguna atau publik, pihak ini biasanya menjadi pihak yang paling sering menjadi korban dari implementasi konvergensi. Persoalan regulasi menyangkut seberapa jauh masyarakat mempunyai hak untuk mengakses media konvergen, dan seberapa jauh distribusi media konvergen mampu dijangkau oleh masyarakat. Termasuk di dalamnya adalah sejauh mana isi media konvergen dapat dipertanggungjawabkan di depan norma dan etika yang berlaku di masyarakat.

Dalam konteks penciptaan regulasi ini, peran para penggiat televisi komunitas dan asosiasi menjadi mutlak diperlukan. Sembari mengembangkan kualitas televisi yang sudah eksis selama ini, mereka dituntut bergerak bersama menyambut konvergensi. Cepat atau lambat, konvergensi akan melanda penyiaran komunitas. Pesimisme akan kondisi kini dan di sini harus dibarengi dengan semangat optimistik bahwa masa depan televisi komunitas akan lebih baik berkat perkembangan teknologi.

\section{KEPUSTAKAAN}

Abrar, N. A. (2003). Teknologi Komunikasi: Perspektif Ilmu Komunikasi. Yogyakarta: LESFI.

Chen, G. M., \& Kai , Z. (2010). "New Media and Cultural Identity in the Global Society" dalam Rotimi Taiwo (Editor) Handbook of Research on Discourse Behavior and Digital Communication: Language Structures and Social Interaction. New York: Information.

Cooper, C. (2018, Juni 24). Gates: Convergence is for Real. Retrieved from CNET.news.com: http://news.com.com/ 2120-7353-3-5137118. htm1

Hastjarjo, S. (2007). Teknologi Digital dan Dunia Penyiaran. Jurnal Komunikasi Massa UNS, Vol. 1, No. 1. 
Jenkins, H. (2006). Convergence Culture: Where Old and New Media Collide. New York: New York University Press.

Romli, K. (2016). Komunikasi Massa. Jakarta: Grasindo.

Sari, M. K. (2016). Peranan Pemilihan Strategi dan Stilistika dalam Iklan di Televisi. REKAM: Jurnal Fotografi, Televisi, dan Animasi, 11(1), 19.

Suprihono, A.E. (2019). Sinematografi Wayang : Persoalan Transmedia Seni Pertunjukan Tradisional. REKAM: Jurnal Fotografi, Televisi, dan Animasi15(2), 131-145.

Severin, J. W., \& James, W. T. (2001). Communication Theories: Origins, Methods, and Uses in Mass Media. New York: Longman.

Tapscott, D. (1996). The Digital Economy Era: Promise and Peril in the Age of Networked Intelligence. New York: McGraw Hill.

Zed, M. (2014). Metode Penelitian Kepustakaan. Jakarta: Yayasan Pustaka Obor Indonesia. 